\title{
PRAÇAS URBANAS - O CASO DA PRAÇA JOÃO MENNA BARRETO- SANTA MARIA-RS - BRASIL - PROCEDIMENTOS METODOLÓGICOS PROJETUAIS PAISAGÍSTICOS APLICADOS À DISCIPLINA DE PAISAGISMO II
}

\author{
PUBLIC PLAZAS - THE CASE OF JOÃO MENNA BARRETO PLAZA - SANTA MARIA-RS \\ - BRASIL LANDSCAPE PROJECT METHODS APPLIED TO THE DISCIPLINE OF LANDSCAPE \\ ARCHITECTURE II
}

\author{
LIMBERGER, Lucienne Rossi Lopes \\ Arquiteta e urbanista, mestre em Planejamento Urbano e Regional pela UFRGS e professora assistente \\ do curso de arquitetura e urbanismo na Universidade Federal de Santa Maria. \\ E-mail: lulimbe@smail.ufsm.br
}

PIPPI, Luis Guilherme A.

Arquiteto e urbanista, mestre em Desenho Urbano e Paisagem pela UFSC e professor assistente do curso de arquitetura e urbanismo na Universidade Federal de Santa Maria.

E-mail:guiamy@hotmail.com

\section{LAZAROTTO, Gerusa}

Arquiteta e urbanista, professora substituta do curso de arquitetura e urbanismo da Universidade Federal de Santa Maria.

E-mail:gelazarotto@yahoo.com.br

\section{RESUMO}

O artigo apresenta os procedimentos metodológicos utilizados na disciplina Projeto de Paisagismo II ministradas no sexto semestre do curso de arquitetura e urbanismo da UFSM. Baseado nos objetivos da disciplina, conhecer e aplicar as variáveis intervenientes na atividade de projetar e ou intervir na paisagem natural e ou construída na contemplação de espaços destinados à praça e /ou via peatonal urbana, a metodologia utilizada busca ressaltar a importância dos espaços abertos públicos na cidade, fundamentais para qualidade de vida urbana. A disciplina trabalha com todas as etapas básicas de um processo projetual paisagístico, e busca a complementação de outros exercícios que possibilitem despertar nos alunos sensibilidade, responsabilidade, senso comunitário e participação solidária para com a paisagem urbana, todos conceitos que devem ser sempre desenvolvidos nas disciplinas de formação acadêmica dos cursos de arquitetura e urbanismo. As etapas permitem aos alunos passar por todas as fases projetuais: do estranhamento do tema até o amadurecimento, possibilitando absorver todas as informações possíveis, considerando a praça como um organismo vivo interagindo com a cidade. Esse despertar para os espaços públicos da cidade é fundamental para nossa formação como arquitetos e urbanistas e, enquanto acadêmicos, possibilita a integração com a comunidade. Para tanto os alunos na disciplina desenvolvem em grupo todos os levantamentos e análises, contemplando um programa de necessidades e desenvolvendo os estudos e detalhamentos necessários para a elaboração do anteprojeto que é apresentado à comunidade em uma exposição, demonstrando o nosso papel em relação a paisagem urbana da cidade.

\section{Palavras-chave: Metodologia projetual paisagística, praças urbanas, comunidade.}

\footnotetext{
ABSTRACT

This paper aims to point out methodological procedures used in the discipline Landscape Architecture Project II, given in the 6th semester of the course of architecture and urbanism of the Federal University of Santa Maria. The methodology utilized, based on the objectives of the discipline, which are to understand and apply the intervening variables in the activity of projecting and intervening in the natural and constructed landscape in the contemplation of spaces for squares and walkways, endeavored to underline the importance of open
} 
public spaces in the city, which are fundamental for the quality of urban life. The discipline deals with all the basic stages of the landscape project process, while complementing with other exercises that allow the students' awakening to the concepts of sensibility, responsibility, a sense of community and solidarity as to the urban landscape. All of these concepts should always be developed in the disciplines of academic formation in courses of architecture and urbanism. The stages give the students the opportunity to pass through all the project stages, from the initial stage of awkwardness with the theme to its maturation, allowing for an absorption of all possible information available, considering the square as a live organism in interaction with the city. This awakening to public spaces in the city is fundamental in the formation of architects and urban designers and, as academics, allows an integration with the community. Thus, the students developed surveys, assessments and analyses, considering necessities and developing the studies and the detailing necessary for the elaboration of a final project. The final project was presented to the community in an exposition, demonstrating our role in relation urban landscape of the city.

\section{Key words: Landscape project methodology, public squares, community.}

\section{1 - Introdução ao método de ensino em Paisagismo}

As disciplinas de Paisagismo do curso de arquitetura e urbanismo da Universidade Federal de Santa Maria - UFSM, até a implantação do novo Plano Político Pedagógico, em maio de 2006, são ministradas a partir do 5o semestre, ou seja na metade do respectivo curso. As mesmas, em número de três, estruturam-se em relação a escala de intervenção e grau de complexidade do programa de necessidades. A disciplina de Paisagismo I desenvolve o anteprojeto paisagístico para uma residência; a de Paisagismo II trabalha com o anteprojeto paisagístico para uma praça inserida no meio urbano consolidado e a de Paisagismo III, desenvolve um anteprojeto paisagístico que contemple o tratamento dos jardins residenciais, das praças e de um parque urbano, para um conjunto habitacional de caráter social. Esta última disciplina acontece no nono semestre do atual currículo do curso, sendo ministrada de forma integrada com as disciplinas: Projeto de Urbanismo III e Projeto de Arquitetura IX que trabalham com reestruturação urbana e proposição de habitações de caráter social em áreas invadidas e/ou de risco. O parque urbano é trabalhado para garantir a sustentabilidade e manutenção da área.

Mas o primeiro contato dos nossos alunos com o espaço aberto e seu entorno, acontece bem mais cedo, ainda no segundo semestre do curso, na disciplina de Projeto de Arquitetura e Urbanismo II, onde é apresentada a metodologia para levantamento e proposição de tratamento para uma praça e seu entorno imediato, com menor grau de complexidade. Com a implantação do novo Plano Político Pedagógico, esse contato acontecerá ainda mais cedo, a partir do primeiro semestre do curso e as demais disciplinas de Paisagismo, desaparecem do currículo, e passam a serem contempladas dentro do grande ateliê - Urbanismo, Paisagismo e Arquitetura.

A descrição da metodologia que vamos apresentar tem sido trabalhada na disciplina Projeto de Paisagismo II, desenvolvida no sexto semestre do curso, dentro do currículo vigente, válido para todos os ingressos até 2005. A disciplina é ofertada uma vez ao ano. A atual metodologia tem sido aplicada nos dois últimos anos. As estratégias de ensino e aprendizagem, baseadas na relação de um professor para cada dez (10) alunos, conforme documento de criação do curso (1992), são desenvolvidas por dois professores arquitetos e urbanistas. São ministradas aulas teóricas e de referência projetual; visitas técnicas (área de estudo, loja de revestimentos para piso e floriculturas, outras que se fizerem necessárias). Os acadêmicos também são responsáveis pela elaboração de seminários e painéis de apresentação e os trabalhos práticos são desenvolvidos em grupo preferencialmente de três alunos.

146 Os objetivos da disciplina Projeto de Paisagismo II são: conhecer e aplicar as variáveis intervenientes na atividade de projetar e/ou intervir na paisagem natural e/ou construída, contemplando espaço destinado a praça e/ou via peatonal urbana. $\bigcirc$ programa de aprendizagem estrutura-se através de duas unidades: a Unidade I que trabalha com os aspectos conceituais como: estudo do tema, revisão bibliográfica, tipologias funcionais, mobiliários e equipamentos 
e programa de necessidades e a Unidade II que constitui o trabalho prático propriamente dito: análise do espaço, estudo preliminar, anteprojeto, infra-estrutura, instalações e equipamentos, detalhamento e representação gráfica.

A Unidade I no estudo de tema e na revisão bibliográfica apresenta a praça como figura urbana no Brasil e no mundo despertando os acadêmicos para a importância da configuração desses espaços na cidade. Os diferentes programas de necessidades bem como as tipologias funcionais das praças, com seus mobiliários e equipamentos também são apresentados e trabalhados como elementos que possibilitam conferir identidade e funcionalidade aos espaços urbanos. Por fim, ainda nesta unidade, são trabalhados alguns conceitos e metodologias possíveis de serem aplicados para elaborar um levantamento da área e identificar todas as necessidades desses espaços na cidade.

A Unidade II constitui-se no trabalho prático propriamente dito, em que todos os aspectos levantados anteriormente são aplicados no processo projetual paisagístico. A bibliografia utilizada para formular a metodologia, de ambas as unidades, foi: Ching (1998), Cullen (1983), Favole (1995), Laurie (1983), Leitão (2002), Mesquita (2000), Macedo (1999), Macedo e Robba (2002), Sá Carneiro e Serra (1996), Santos e Teixeira (2001), Longhi (1995), Lorenzi (1992, 1995, 2003).

\section{2 - Procedimentos metodológicos de ensino para a disciplina de Paisagismo II}

Baseados nas estratégias de ensino, adotadas na disciplina de Paisagismo II, descritas acima, as unidades estruturam-se em oito etapas metodológicas que compreendem:

ETAPA 1- Referências teóricas e projetuais

ETAPA 2 - Visitação a área de intervenção - metodologia, levantamento e análise

ETAPA 3 - Elaboração do programa de necessidades

ETAPA 4 - Ficha de vegetação

ETAPA 5 - Partido geral

ETAPA 6 - Anteprojeto paisagístico para praça

ETAPA 7 - Detalhamento

ETAPA 8 - Exposição didática na praça João Menna Barreto

Estas etapas, apesar de serem bem distintas, se sobrepõem em diversos momentos da disciplina e são desenvolvidas individualmente e/ou em grupo de três ou mais componentes, dependendo da etapa. A seguir apresentaremos os temas, objetivos e justificativas de cada das etapas.

\section{1 - Etapa 1 - Referências projetuais}

Nesta primeira etapa, é apresentado o embasamento teórico e as referências projetuais do tema - praças urbanas: conceitos fundamentais, funções das praças, os diferentes papeis das praças na cidade, histórico, evolução e estudos de caso de praças urbanas no Brasil e no Mundo. As aulas são ilustradas e os alunos são estimulados a participar através de comentários e discussões sobre os exemplos apresentados. Esta etapa proporciona um embasamento da turma com a formação teórica e do repertório projetual, mas também permite que os acadêmicos identifiquem os fatores que interferem no processo metodológico para levantamento e análise crítica do espaço a sofrer intervenção e de seu entorno imediato.

\section{2 - Ełapa 2 - Visita à área de estudo - Metodologia, levantamento e análise}

Nesta etapa avaliativa, os acadêmicos têm o primeiro contato com a área a sofrer intervenção: a praça João Menna Barreto localizada em área central de cidade de Santa Maria-RS. Os princi- 
pais objetivos são: conhecer os métodos e instrumentos básicos necessários à intervenção em espaços abertos públicos e compreender os elementos componentes e os fatores condicionantes da paisagem natural e construída, quanto as suas características físicas (sítio, microclima, topografia, vegetação); ao processo de ocupação da área (histórico, edificações, espaços abertos, conexões, circulações, equipamentos urbanos, mobiliários, etc.); aos usos/demandas e outros. As tarefas são desenvolvidas em grupo, com seis integrantes e apresentadas em seminários. Cada um dos grupos, para entender a dinâmica do processo de ocupação e consolidação da área, é responsável pelo levantamento e a análise dos seguintes aspectos:

Grupo 1 - Histórico - responsável pelo levantamento e descrição de todo o processo de ocupação e inserção da área na malha urbana, pela caracterização da volumetria e usos do entorno na época do projeto, pela identificação dos usuários e função da praça e pela descrição da linha projetual adotada, bem como: ano, autores do projeto e se o mesmo sofreu alterações no projeto original. $\bigcirc$ grupo ainda é responsável pela aplicação de um questionário para identificar as aspirações da população, os fluxos, as circulações e os impactos e potencialidades da área a sofrer intervenção. As fontes consultadas para auxiliar na elaboração do trabalho foram: Arquivo Histórico, Prefeitura e Secretarias Municipais, fotos e jornais de época, a comunidade e as referências metodológicas e teóricas projetuais trabalhadas na Unidade I.

Grupo 2 - Levantamento físico - responsável pelo levantamento e descrição da morfologia do terreno (medição e representação bidimensional da área) topografia, acessos e os limites físicos da área. São também identificados os condicionantes climáticos como: orientação solar, direção dos ventos, vegetação existente (volumetria, espécies existentes e a serem conservadas), visuais, presença de elementos naturais (formação vegetal, recursos hídricos, aflorações e outros). As fontes consultadas para auxiliar na elaboração do trabalho foram: Prefeitura e Secretarias Municipais, medição direta, carta bioclimática (temperatura e umidade relativa), carta dos ventos (direção e intensidade dos ventos), dados de radiação solar da localidade, levantamento das espécies vegetais existentes e tombadas, fotos da área e as referências metodológicas e teóricas projetuais trabalhadas na Unidade I.

Grupo 3 - Entorno, infra-estrutura e mobiliário urbano - responsável pelo levantamento e descrição de todos os elementos existentes no entorno e no espaço a sofrer intervenção: postes de iluminação, boca de lobo, rampas, pontos de ônibus, mobiliário (bancos, lixeiras, bebedouros, sinalização, monumentos, outros). Esse grupo também é responsável pela identificação da situação atual do entorno, volumetria e uso das edificações, acessos e percursos utilizados. As fontes consultadas para auxiliar na elaboração do trabalho foram: Prefeitura e Secretarias Municipais, companhias de fornecimento (água, esgoto, eletricidade, outras), companhias de transporte público, fotos dos elementos existentes no local e no entorno, comunidade e as referências metodológicas e teóricas projetuais trabalhadas na Unidadel.

Grupo 4 - Maquete - tem por finalidade representar tridimensionalmente o levantamento físico da área e do seu entorno, a partir dos levantamentos realizados pelos demais grupos. A maquete tridimensional auxilia no desenvolvimento da proposta de intervenção para a área de estudo, possibilitando tirar duvidas em relação a uma série de fatores como: topografia, acessos, massas vegetais existentes, volumetria do entorno entre outros.

\section{3 - Etapa 3 - Programa de necessidade}

Não constitui uma etapa avaliativa, tendo sido elaborada, após a apresentação da Etapa 2 , em conjunto pelos professores e alunos da disciplina. $\bigcirc$ programa de necessidades foi estruturado a partir dos problemas identificados no levantamento. Para cada problema foram elaboradas diretrizes e soluções espaciais descritas no quadro abaixo: 


\begin{tabular}{|c|c|c|}
\hline PROBLEMAS IDENTIFICADOS & DIRETRIZES & SOLUÇÕES \\
\hline topografia & $\begin{array}{l}\text { proporcionar acessos a todos os } \\
\text { ambientes por todos os usuários }\end{array}$ & platôs, rampas, escadas, desníveis \\
\hline portadores necessidades especiais & $\begin{array}{l}\text { proporcionar acessos e possibilidade } \\
\text { de utilização de todos os ambientes, } \\
\text { mobiliário e equipamentos }\end{array}$ & $\begin{array}{l}\text { rampas, banheiros, bebedouros, } \\
\text { telefones, bancos, outros pertinentes }\end{array}$ \\
\hline falta de insolação & $\begin{array}{l}\text { rever vegetação existente } \\
\text { trabalhar luz e sombra na praça }\end{array}$ & $\begin{array}{l}\text { retirar as espécies em mau estado } \\
\text { implantar espécies adequadas aos } \\
\text { usos e ambientes propostos }\end{array}$ \\
\hline interferência de usos & $\begin{array}{l}\text { estimular uso dos ambientes de } \\
\text { forma estruturada evitando concor- } \\
\text { rência entre os usuários }\end{array}$ & $\begin{array}{l}\text { propor ambientes adequados as ne- } \\
\text { cessidades existentes e aos diferentes } \\
\text { usuários da praça }\end{array}$ \\
\hline banheiros e equipamentos & rever as instalações e localização & $\begin{array}{l}\text { banheiros adequados a todos os } \\
\text { usuários: número e instalações }\end{array}$ \\
\hline mobiliário & $\begin{array}{l}\text { adequar aos diferentes ambientes e } \\
\text { usuários (faixas etárias) }\end{array}$ & $\begin{array}{l}\text { mobiliário adequado as atividades } \\
\text { propostas nos ambientes }\end{array}$ \\
\hline infra-estrutura & refazer infra-estrutura & $\begin{array}{l}\text { infra-estrutura adequada as novas } \\
\text { necessidades da praça }\end{array}$ \\
\hline manutenção & $\begin{array}{l}\text { prever pessoal para manutenção e } \\
\text { fiscalização }\end{array}$ & espaço para zeladoria \\
\hline tratamento paisagístico & $\begin{array}{l}\text { propor espécies vegetais e revesti- } \\
\text { mentos adequados aos ambientes } \\
\text { propostos }\end{array}$ & $\begin{array}{l}\text { espécies vegetais e pisos adequa- } \\
\text { dos aos usuários e funções dos } \\
\text { ambientes }\end{array}$ \\
\hline faixas etárias diversificadas & $\begin{array}{l}\text { criar ambientes atrativos estimulando } \\
\text { o lazer, a recreação e a convivência } \\
\text { entre os grupos }\end{array}$ & $\begin{array}{l}\text { espaço configurados mas ao mesmo } \\
\text { tempo com a possibilidade de serem } \\
\text { integrados }\end{array}$ \\
\hline animais soltos & $\begin{array}{l}\text { definir áreas próprias evitando } \\
\text { conflitos }\end{array}$ & espaço para os animais domésticos \\
\hline mau cheiro & $\begin{array}{l}\text { educação, manutenção preventiva e } \\
\text { controle dos usos }\end{array}$ & $\begin{array}{l}\text { novas instalações, zeladoria e a } \\
\text { comunidade usuária }\end{array}$ \\
\hline insegurança & $\begin{array}{l}\text { fiscalização preventiva e controle } \\
\text { dos usos }\end{array}$ & zeladoria e a comunidade usuária \\
\hline vandalismo & $\begin{array}{l}\text { propor espaços com usos adequa- } \\
\text { dos e consolidados pela comuni- } \\
\text { dade }\end{array}$ & $\begin{array}{l}\text { ambientes e mobiliário pertinentes, } \\
\text { zeladoria, fiscalização }\end{array}$ \\
\hline exclusão social & $\begin{array}{l}\text { propor espaços para educação } \\
\text { social e ambiental }\end{array}$ & $\begin{array}{l}\text { propor ambiente multiuso, atividades } \\
\text { coorporativas, placas para identi- } \\
\text { ficação das espécies e sinalização } \\
\text { ambientes }\end{array}$ \\
\hline
\end{tabular}

Estruturou-se para a Praça João Menna Barreto o seguinte programa de necessidades:

- Playground (setorizado/nivelado);

- espaço coberto multiuso (oficinas, feiras, exposições, teatro de rua, outros);

- espaço aberto multiuso;

- espaço para jogos;

- áreas ensolarada e sombreadas (lazer passivo e ativo);

- infra-estrutura adequada: pontos de água (bebedouro, banheiro, outros), luz, telefone;

- bancos adequados as diferentes funções;

- iluminação; 
- espaço para passeio, adestramento e recreação dos animais;

- banheiro (um por sexo e adaptado aos portadores de necessidades especiais);

- zeladoria;

- local dos taxistas/banheiros.

\section{4 - Etapa 4 - Ficha de vegetação}

Nesta etapa avaliativa, é feito um trabalho prático a partir do embasamento teórico e das referências trabalhadas nas aulas como: estruturas vegetais, arborização do espaço público (praças e ruas), arbóreas locais - Unidade I - Santos e Teixeira (2001), Longhi (1995), Lorenzi (1992, 1995, 2003). A etapa também contempla uma aula prática - denominada "passeio" pelo campus da UFSM que permite a identificação e fixação das espécies vegetais estudadas, através da observação e representação gráfica (ver Figura 1). A Ełapa 3 é concluída com a aplicação de um exercício que consiste em elaborar uma ficha de vegetação. As espécies catalogadas, em número mínimo de dez por aluno, são de livre escolha desde que nativas - arbóreas, palmeiras e arbustivas. A ficha contempla dois momentos: a representação gráfica (vistas, planta baixa, detalhes: flor, fruto, folha) a identificação da espécie (nome científico; nome popular; grupo vegetal; uso; ordem; origem; outros) (ver Figura 2). Também deve apresentar a localização de cada espécie através do endereço e fotografia.

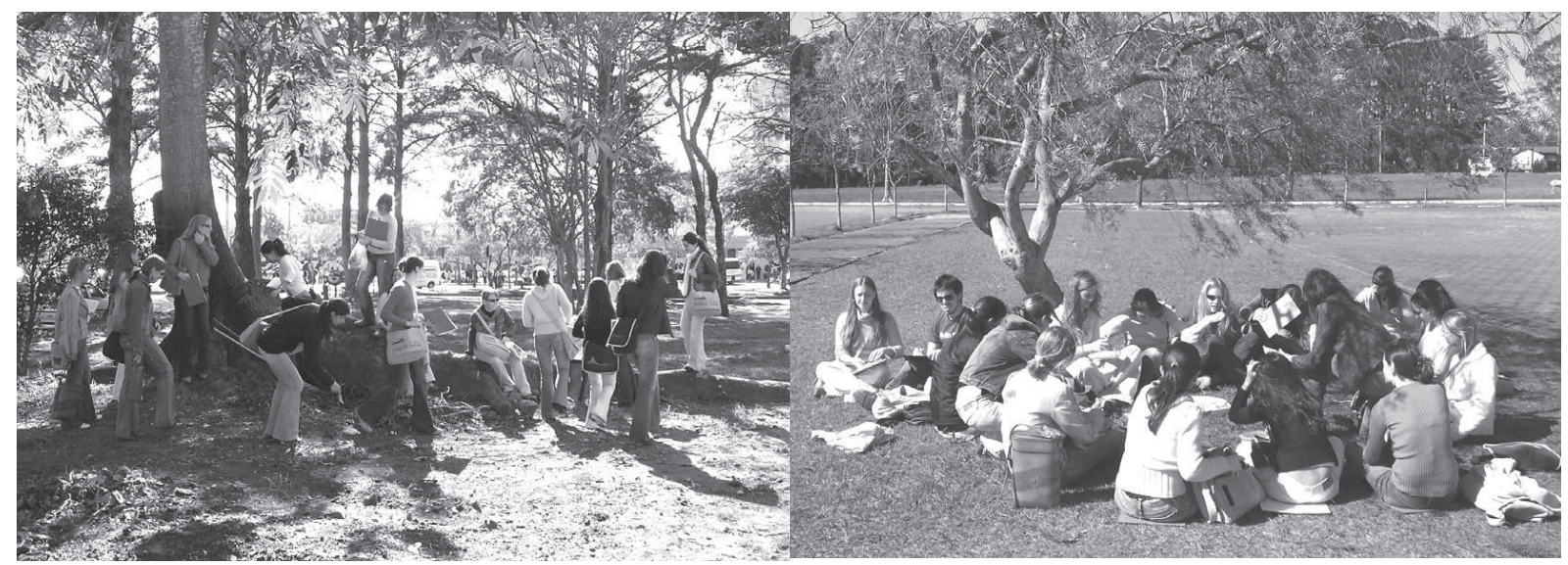

Figura 1: Passeio pelo campus da UFSM - observação das espécies vegetais

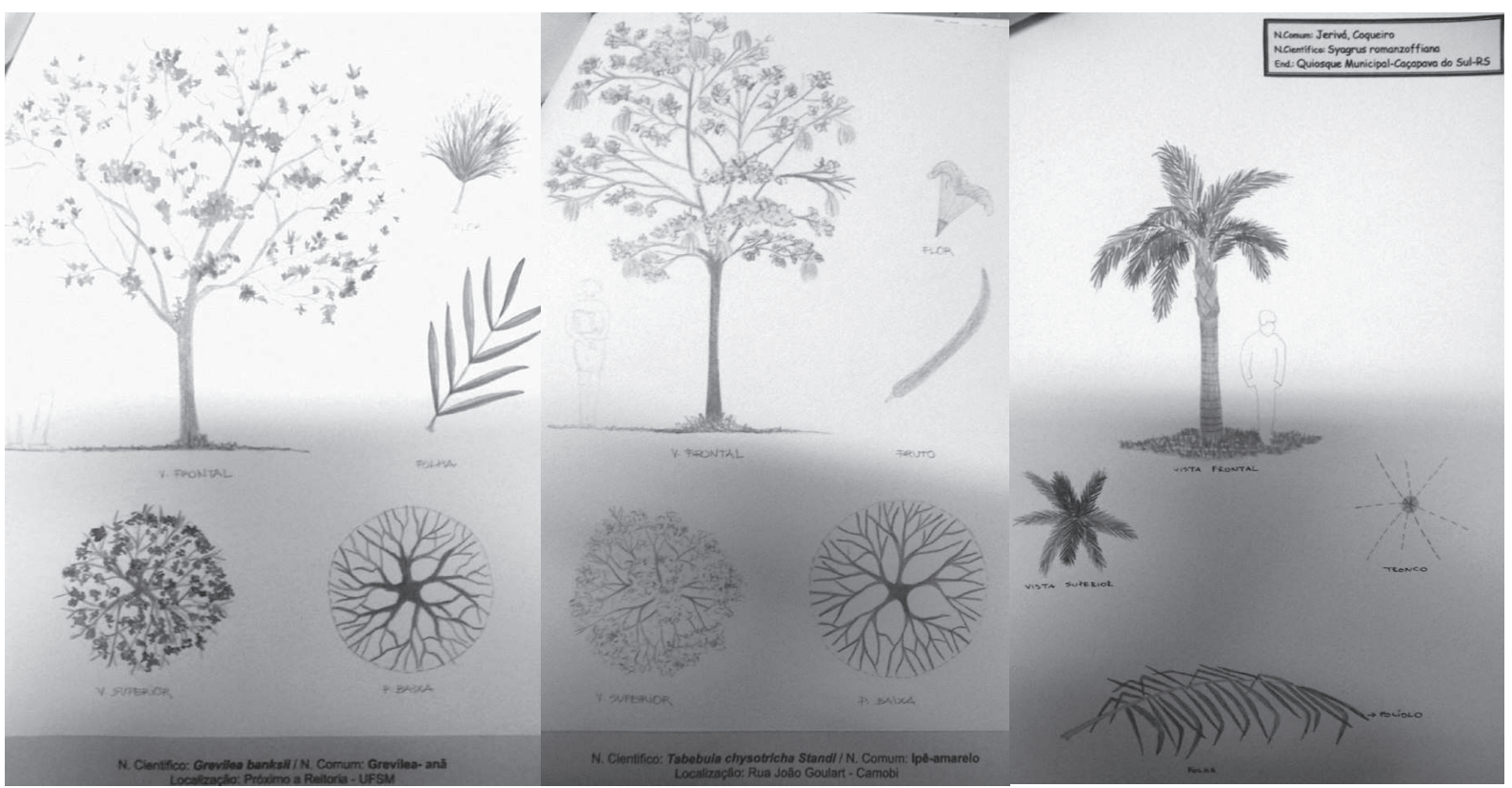

Figura 2: Ficha de vegetação - representação gráfica à mão livre das espécies vegetais observadas 
O objetivo da elaboração da ficha é servir de subsídio para definição das espécies a serem utilizadas no projeto e despertar o interesse nos alunos pelas cores, estruturas, texturas dos troncos, folhagens e florações, proporcionando uma representação gráfica mais adequada, embasada em dimensões aproximadas do diâmetro de copa e altura das espécies a serem representadas na implantação, em planta baixa, nas elevações e na maquete.

\section{5 - Etapa 5 - Partido arquitetônico}

Esta etapa não é avaliativa, apenas sinaliza o andamento do projeto e tem por objetivo mostrar as idéias geradoras da proposta de forma clara e simplificadas, a partir do programa de necessidade. É a primeira aproximação da solução pretendida para a área de intervenção, são apresentados todos os elementos que possibilitam o entendimento da proposta: zoneamento das atividades, a relação com o entorno, a definição do público alvo (usuários), as massas de vegetação, a modelagem do terreno e todas as demais informações necessárias para o entendimento da mesma. A linguagem gráfica adotada é o desenho a mão livre e em escala compatível, na qual o aluno consiga demonstrar a proposta e seu entorno imediato, o conjunto como um todo. No caso da praça estudada a escala utilizada foi 1:250.

Apresenta-se nesta etapa a evolução do princípio gerador da proposta (eixos imaginários e fundamentos do lançamento da proposta); o zoneamento básico da praça e a volumetria proposta (ver Figura 3). A planta de localização identificando a relação da praça com seu entorno imediato, planta baixa, elevações (representando a volumetria das espécies vegetais propostas), cortes (mostrando desníveis do terreno, volumetria das espécies vegetais e o entorno imediato), bem como croquis, perspectivas gerais e maquete volumétrica da proposta são apresentadas nessa etapa (ver Figuras 4, 5 e 6). Também é apresentada uma tabela com as áreas permeáveis, impermeáveis e totais da praça e um memorial de intenções com uma conceituação fundamentada da proposta de projeto paisagístico, contemplando todos os espaços definidos no programa de necessidades e justificando as tomadas de decisões no projeto. Nesta etapa a vegetação é apresentada em relação ao seu uso, estrutura (sombreamento, marcação, ornamental, vedação, atração avifauna, alimentação, outros), volume, cor, texturas, não é necessário, determinar quais são as espécies utilizadas no projeto, e sim qual o efeito pretendido, por cada grupo, na composição da praça.

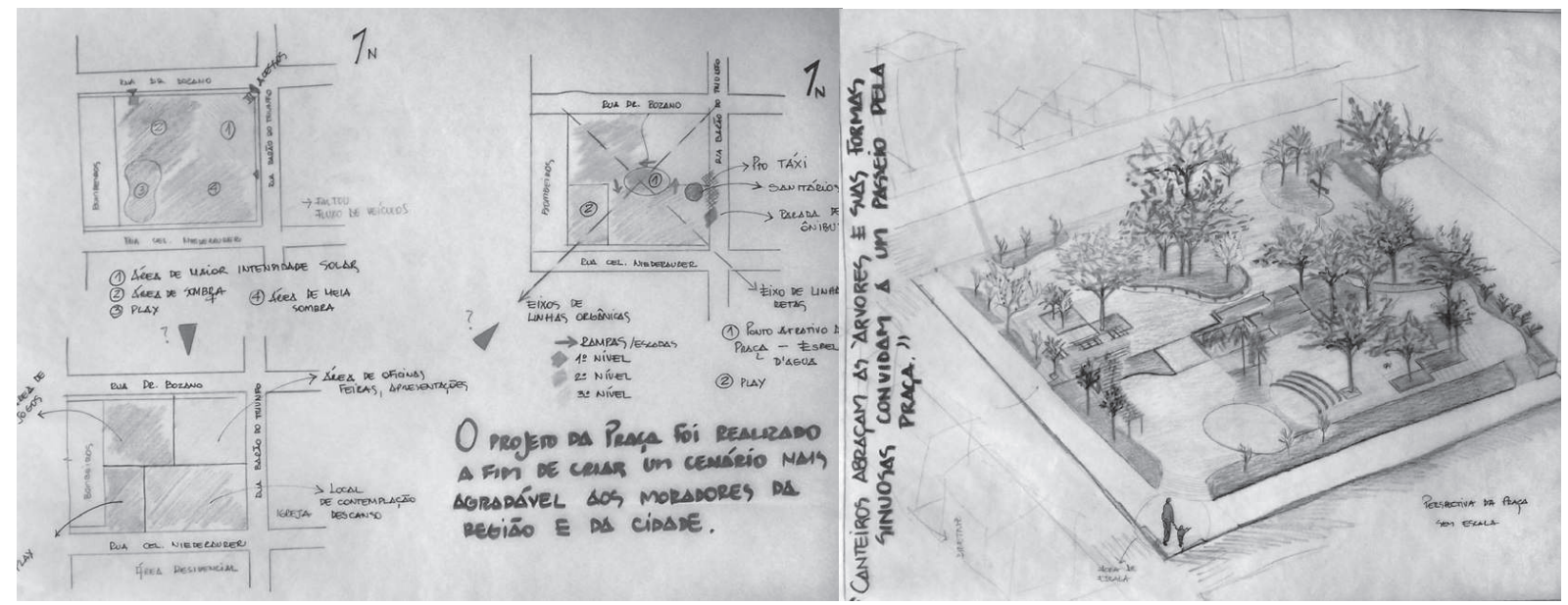

Figura 3: Partido Arquitetônico - princípio gerador da proposta, fluxos e zoneamento do programa de necessidades e perspectiva

Nesta etapa seis diferentes partidos arquitetônicos foram propostos, às figuras abaixo ilustram alguns dos elementos apresentados em cada um desses partidos (ver Figuras 4, 5 e 6). 

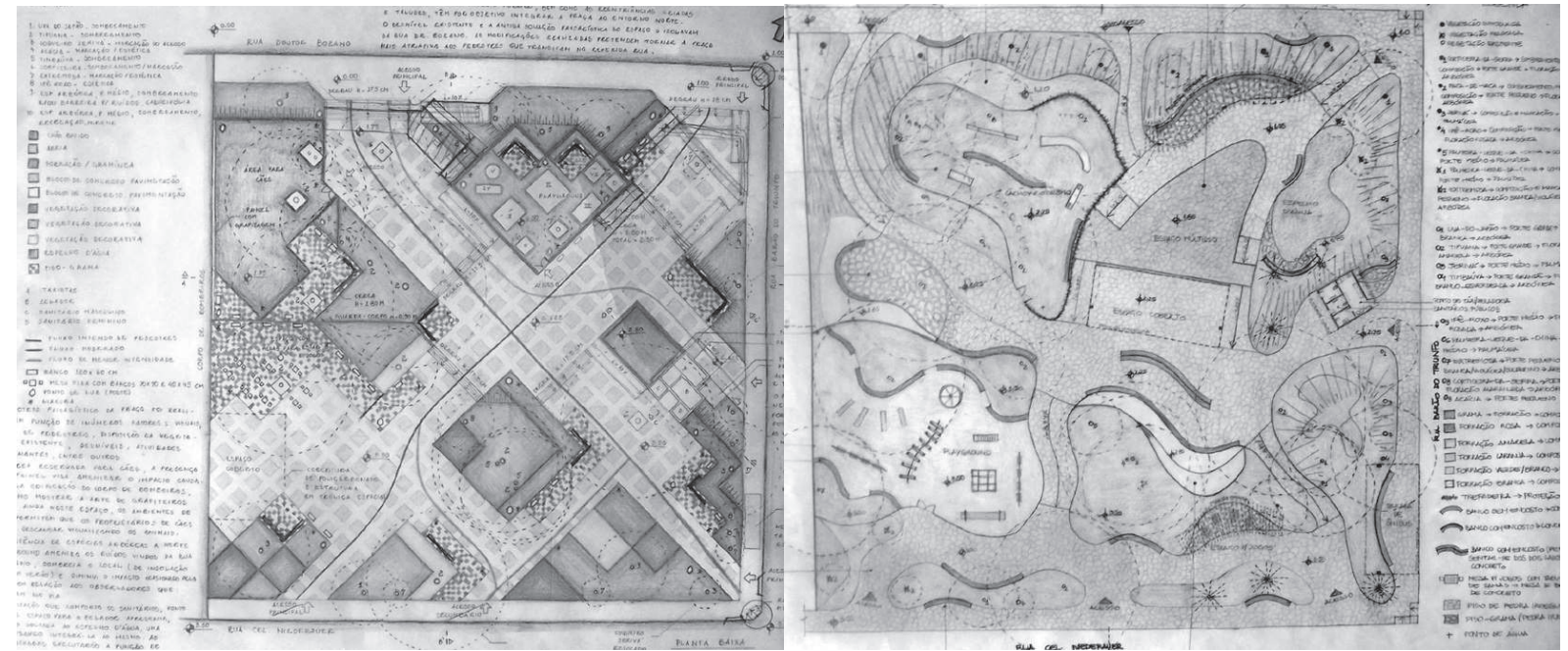

Figura 4: Partido Arquitetônico - planta baixa - proposta em malha a 45 graus e orgânica

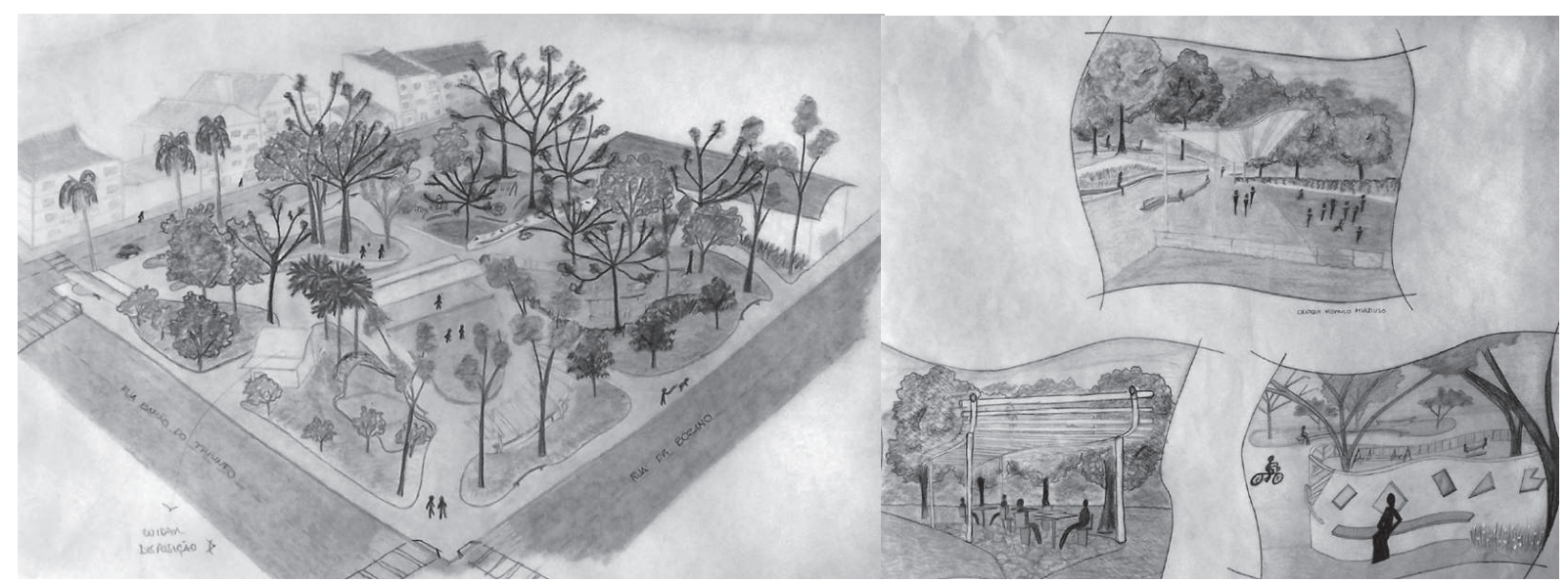

Figura 5: Partido Arquitetônico - perspectiva e croquis

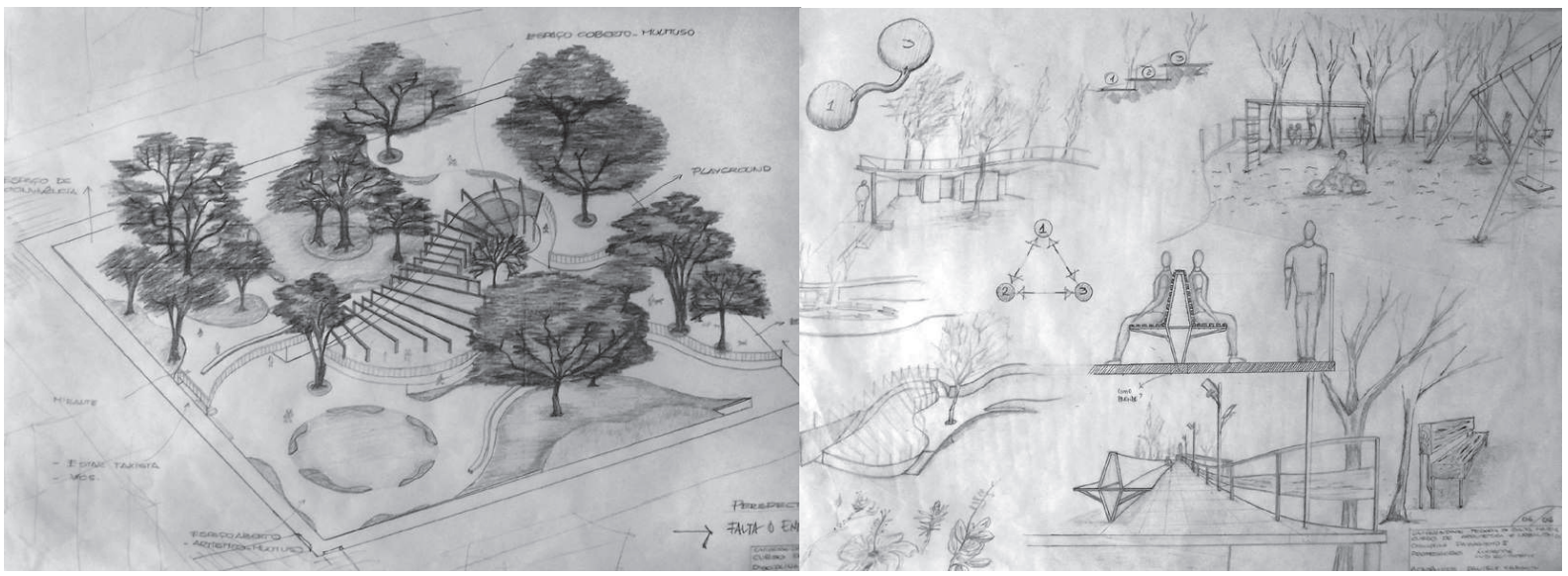

Figura 6: Partido Arquitetônico - perspectiva e croquis

\section{6 - Etapa 6 - Anteprojeto}

Nesta etapa avaliativa, o grupo apresenta todos os elementos necessários para a compreensão total da proposta projetual. São feitos dois tipos de avaliações: qualitativa e quantitativa.

A avaliação qualitativa da proposta se estrutura a partir dos seguintes elementos: atendimento ao programa de necessidades; proposta de projeto fundamentada; originalidade nas soluções apresentadas; funcionalidade do projeto; organização espacial e viabilidade de execução. 
A avaliação quantitativa refere-se aos elementos mínimos de entrega que devem ser contemplados pelo grupo: planta de localização, planta geral de implantação, planta de locação dos elementos construídos (técnica), planta de locação da vegetação (técnica), elevações, cortes setoriais e gerais, perspectiva da praça, edificações e equipamentos públicos propostos em planta baixa, corte e fachadas, croquis perspectivos dos espaços mais significativos do projeto, maquete da proposta (ver Figuras 7, 8 e 9), e memorial das espécies vegetais. Nesta etapa as espécies são identificadas e apresentadas no quadro da vegetação com: nome científico, nome popular, grupo

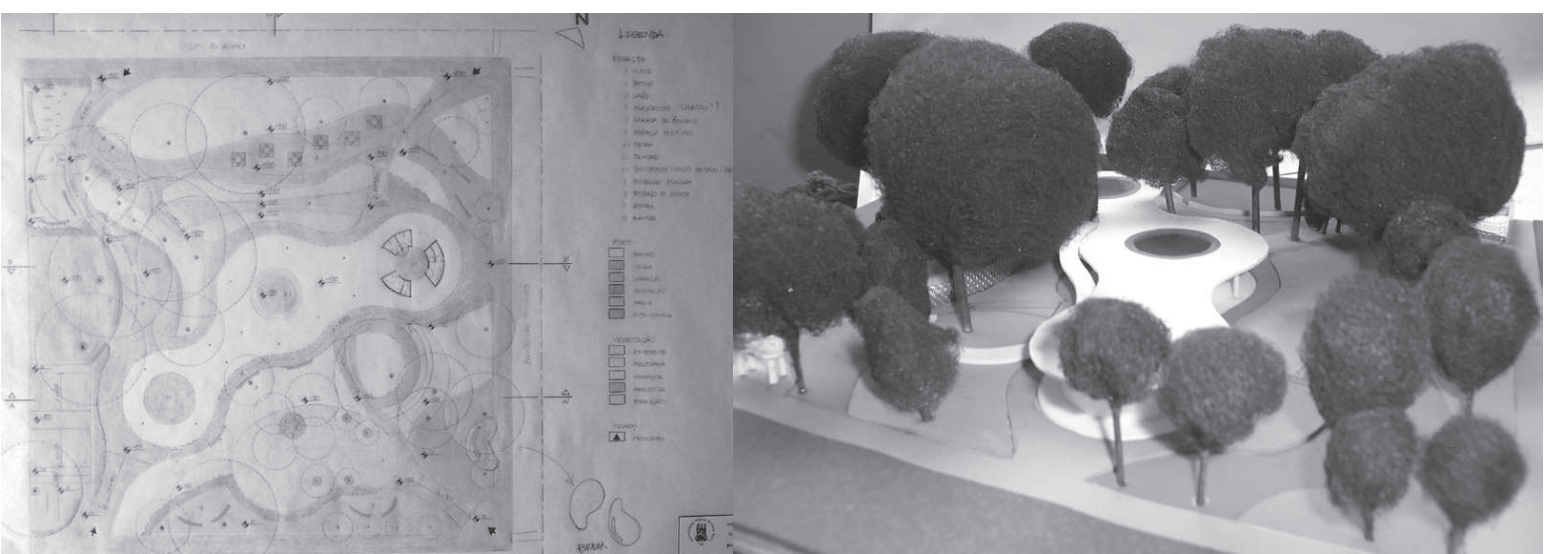

Figura 7: Anteprojeto - planta baixa com legenda e maquete final

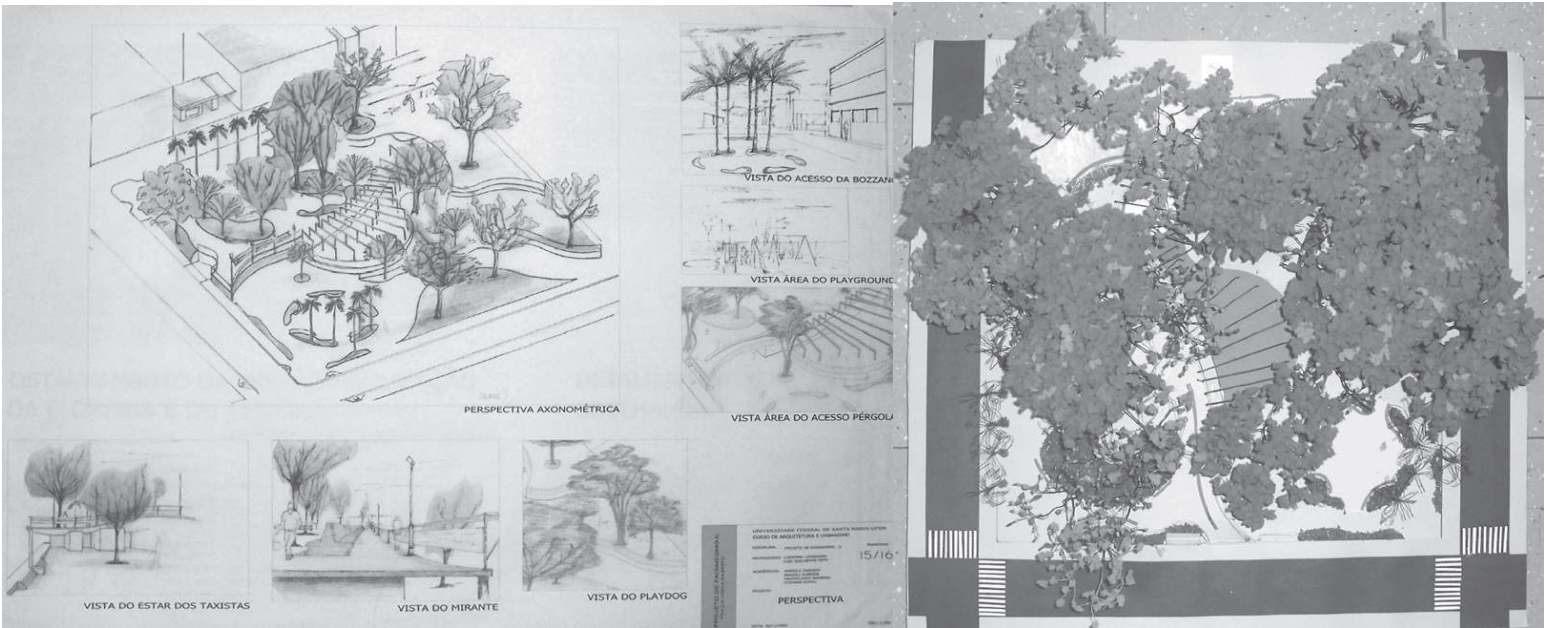

Figura 8: Anteprojeto - perspectiva geral da praça, croquis e maquete final

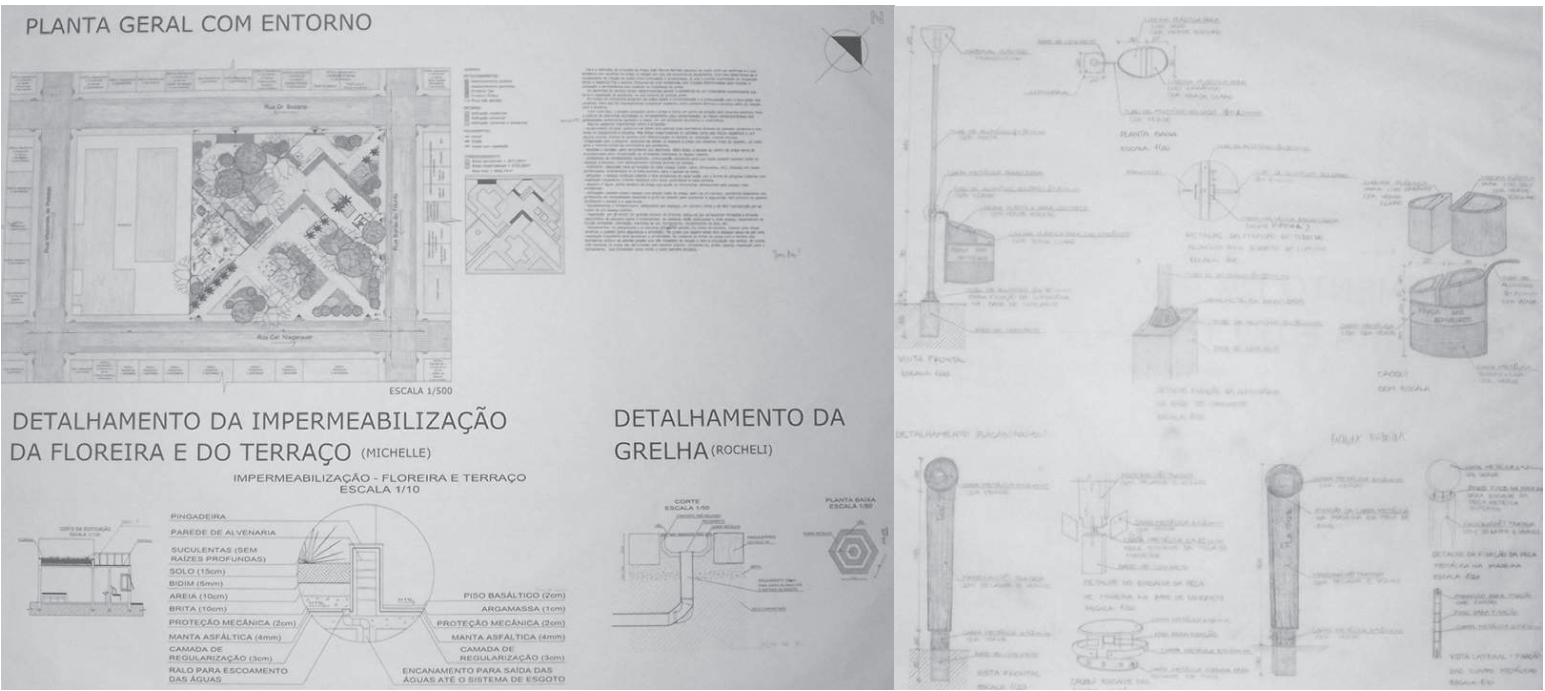

Figura 9: Anteprojeto e detalhamento 
vegetal, procedência (exótica ou nativa), folhagem (perene ou caducifólia), floração (época e cor), uso no projeto (função sombreamento, marcação, mancha de cor, recobrimento do solo, etc), outras observações pertinentes. A linguagem gráfica adotada é de livre escolha do grupo, desde que atenda as solicitações necessárias para entendimento da proposta.

\section{7 - Etapa 7 - Detalhamento}

Nesta etapa, a avaliação é individual sendo o grupo desmembrado. No primeiro momento, os professores junto com o grupo elencaram os elementos mais relevantes do anteprojeto a serem detalhados. Por exemplo: pavimentações (piso grama, pedra, pisos informais, outros), elementos construídos (escadas, rampas, floreiras, espelhos d'água, decks, pérgulas, quiosques, fechamentos, outros), mobiliário (bancos, bebedouro, mesa de jogos, luminárias, lixeiras, brinquedos do playground, equipamentos de ginástica, corrimão, guarda-corpo, painéis informativos, para da de ônibus, outros).

Cada membro do grupo fica encarregado de fazer, no mínimo, três grupos de detalhes. $\bigcirc$ detalhamento deve apresentar os materiais utilizados, as dimensões, forma de fixação, a área útil para cada equipamento, etc. $\bigcirc$ objetivo desta etapa é despertar o aluno para a importância das especificações técnicas, de explicitar quais as soluções que possibilitam a viabilização de sua proposta projetual (ver Figura 9).
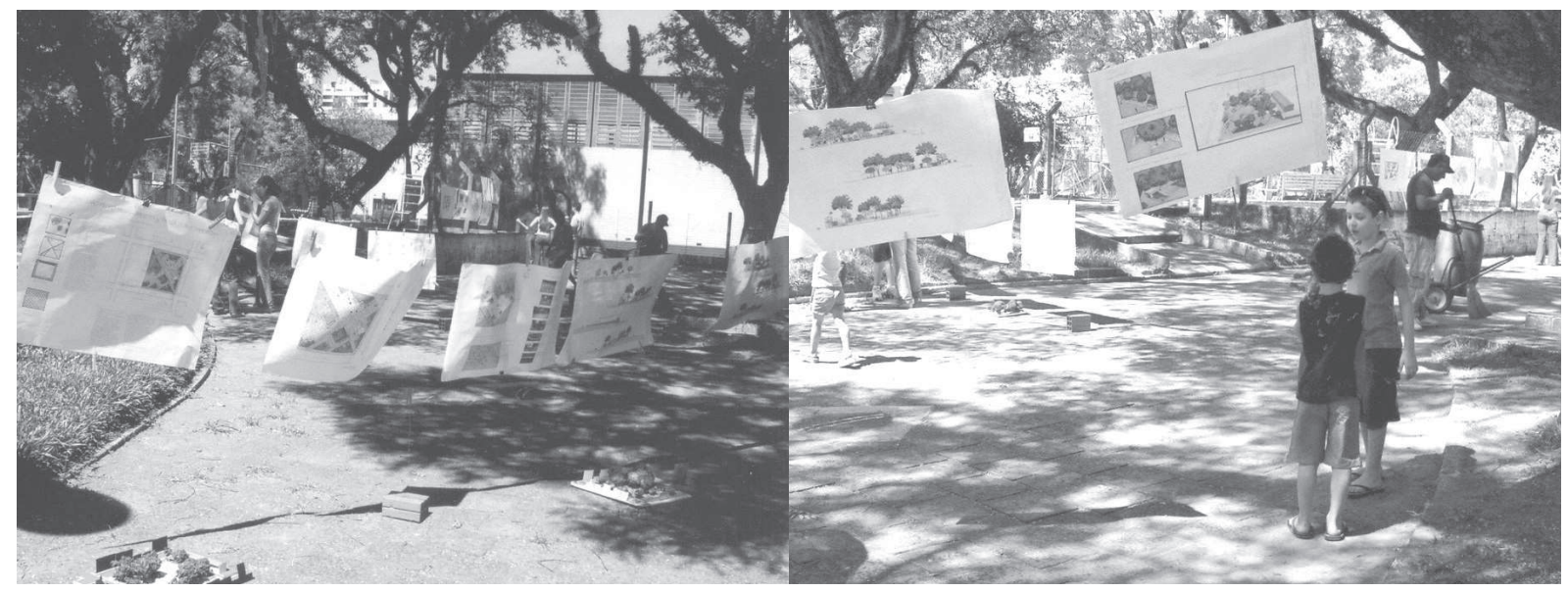

Figura 10: Exposição dos trabalhos - pranchas e maquetes

\section{8 - Etapa 8 - Exposição didática na praça João Menna Barreto}

Esta etapa sempre foi planejada, em edições anteriores da disciplina, mas foi à primeira vez que conseguimos expor os trabalhos no mesmo local em que propomos a intervenção (ver Figura 10), possibilitando aos alunos explicar as propostas no próprio local para a comunidade. A participação dos alunos nessa etapa é livre, já que nesse momento os trabalhos já foram avaliados e as notas publicadas. Apesar dessa liberdade e da exposição ter acontecido em um domingo pela manhã, tivemos representantes de todos os grupos. A experiência, além de proporcionar novamente a integração com a comunidade, proporcionou a participação na exposição dos familiares e amigos dos alunos e professores tendo sido noticiada pela imprensa local.

\section{3 - Conclusão}

O embasamento teórico e de referências projetuais sobre o tema - praças urbanas proporcionou, além da formação de um repertório básico, a integração entre a turma que passou a analisar e discutir os projetos apresentados de forma crítica, contextualizando as propostas. 
Praças Urbanas - O Caso da Praça João Menna Barreto Santa Maria-RS - Brasil

A estruturação dos grupos para desenvolverem as etapas projetuais paisagísticas era de seis grupos com três alunos cada. No decorrer do processo a configuração dos grupos se modificou com a chegada de um aluno de intercâmbio (Santas Fé-Argentina) contribuiu para a troca de idéias e vivências sobre os espaços abertos públicos na cidade.

O levantamento e análise proporcionaram uma série de informações físicas, históricas e vivenciais, ou seja, o contato direto dos alunos com a comunidade, uma atividade comum nos projetos de extensão que pode ser vivenciada dentro da disciplina. A praça tem uma série de condicionantes tais como: uma das laterais é configurada pelo pavilhão do corpo de bombeiros (por isso a praça também é conhecida como praça dos Bombeiros); tem uma série de espécies arbóreas a serem preservadas; sombreamento excessivo; ponto de táxi e parada de ônibus a serem mantidos; sanitários em péssimo estado de conservação, bem como pavimentação, acesso, mobiliário, iluminação, pontos de água deficientes. Outro problema constatado é a presença de animais domésticos (soltos ou acompanhados) ocasionando mau cheiro em locais de estar e nas circulações. Somam-se a isso a sobreposição das diferentes atividades desenvolvidas na praça, sem nenhuma infra-estrutura para as mesmas: feira de hortifrutigranjeiro (semanalmente), feira de filhotes (semanalmente), pracinha de brinquedos, outras.

A montagem do programa de necessidades, em grupo na sala de aula, permitiu uma discussão e integração da turma, cada um querendo contribuir com sua vivência e questionando as diferentes formas de utilização do espaço, constatadas a partir da observação no local e colocações da comunidade entrevistada. A partir do programa cada grupo teve liberdade para definir quais as principais diretrizes para seu projeto paisagístico. Essa flexibilidade originou seis propostas projetuais, bem diferentes, para a praça João Menna Barreto.

A ficha de vegetação retomou as referências trabalhadas em aula (estruturas vegetais, arborização do espaço público (praças e ruas), arbóreas locais) e proporcionou, através do passeio pelo campus da UFSM, a identificação e fixação das espécies vegetais estudadas. Essa etapa permitiu uma maior aproximação e o despertar do interesse dos alunos pelas cores, estruturas, texturas, folhagens e florações através da observação e representação gráfica das mesmas, bem como a posterior catalogação. O passeio terminou em um piquenique no campus.

Nos seis partidos arquitetônicos apresentados foi possível mostrar as idéias geradoras, de forma simplificada, cada uma com uma abordagem diferente dos problemas identificados. Esta etapa apresentou a primeira aproximação da solução pretendida para a área de intervenção pelos grupos, através da entrega e defesa oral das propostas.

O anteprojeto e o detalhamento apresentaram os demais elementos necessários para o entendimento da proposta de intervenção paisagística para a praça João Menna Barreto. A etapa de detalhamento despertou o interesse dos alunos em relação às especificações técnicas, buscando explicitar as soluções técnicas utilizadas para viabilizar a proposta projetual.

A exposição didática que aconteceu na praça João Menna Barreto, no dia 18 de dezembro de 2006, em um domingo pela manhã, possibilitou aos alunos e professores dar um retorno à comunidade, através da apresentação das diferentes propostas projetuais paisagísticas na própria praça.

Os alunos tiveram a oportunidade de apresentar e defender suas idéias projetuais perante a comunidade. A comunidade ficou satisfeita em ver seis propostas diferentes para a praça. Este momento de troca e interação foi muito importante para reforçar o elo entre a universidade e a comunidade, demonstrando as potencialidades dos futuros profissionais arquitetos, paisagistas e urbanistas. Ao mesmo tempo a exposição serviu para sensibilizar a comunidade a buscar uma revitalização adequada e duradoura para a praça, levando em consideração as reais necessidades da área, seu entorno e usuários. 
Procedimento metodológico adotado permitiu o amadurecimento dos alunos ao longo do processo projetual paisagístico. As seis propostas diferenciadas foram uma grata surpresa para a comunidade, contemplando todas as necessidades dos usuários e solucionando os impactos existentes, entretanto se mostraram deficientes em relação ao entorno imediato, pois os mesmos não conseguiram extrapolar os limites da praça, calçadas e adjacências (faixa de segurança, marcação de cruzamentos, redutores de velocidade, rampas para portadores de necessidades especiais, outros).

Cabe a nós professor apresentar algumas metodologias e etapas projetuais paisagísticas, buscando formar profissionais sensíveis e capazes de atuar no mercado de trabalho com responsabilidade técnica.

Assim, acreditamos estar capacitando futuros profissionais para projetar adequadamente e com responsabilidade os espaços abertos públicos, fundamentais para a nossa cidade, contribuindo para a qualidade de vida urbana das atuais e futuras gerações.

\section{Bibliografia}

ADAMS, William Howard. Roberto Burle Marx: The unnatural art of the garden. Nova York: The Museum of Modern Art New York, 1991.

CHING, F. Arquitetura, forma, espaço e ordem. São Paulo: Martins Fontes, 1998.

CULLEN, G. A paisagem urbana. Arquitetura e urbanismo. São Paulo: Livraria Martins Fontes Editora Ltda, 1983. $200 p$.

FAVOLE, P. La plaza en la arquitectura contemporanea. Barcelona: Editorial Gustavo Gilli S. A., 1995.

LAURIE, Michael. Introducción a la arquitectura del paisaje. Barcelona: Editorial Gustavo Gilli S. A., 1983.

LEITÃO, Lúcia (Org.). As praças que a gente tem, as praças que a gente quer: Manual de procedimentos para intervenção em praças. Recife: Secretaria, 2002.

LITTLEWOOD, M. Diseño Urbano 1. Muros y Cerramientos - Detalles. México: Gustavo Gilli S. A. de C.V., 1994.

Diseño Urbano 3. Árboles. México: Detalles. Gustavo Gilli S.A. de C.V. 1995, 187p.

LONGHI, Rubens Alberto. Livro das árvores. Árvores e arvoretas do Sul. Porto Alegre: L \& PM Editores, 1995.

LORENZI, Harri; SOUZA, Hermes Moreira de. Plantas ornamentais no Brasil: Arbustivas, herbáceas e trepadeiras. Nova Odessa: Editora Plantarum, 1995.

2. ed. Nova Odessa: Editora Plantarum, 1999.

Árvores brasileiras - Manual de identificação e cultivo de plantas arbóreas nativas do Brasil. São Paulo: Editora Plantarum, 1992.

LORENZI, Harri et. al. Árvores exóticas no Brasil: Madeireiras, ornamentais e aromáticas. Nova Odessa/São Paulo: Instituto Plantarum Ltda., 2003.

Palmeiras brasileiras e exóticas cultivadas. Nova Odessa-São Paulo: Instituto Plantarum Ltda., 2004.

Palmeiras no Brasil. Nativas e exóticas. Nova Odessa-São Paulo: Editora Plantarum Ltda., 1992.

MACEDO, Silvio Soares (Org.). Quadro do paisagismo no Brasil. São Paulo: Quapá, São Paulo, 1999.

digital).

. (Coord.). Quapá. Paisagem contemporânea no Brasil - Projeto Quapá. São Paulo: FAUUSP, 2003. (meio

MACEDO, Silvio Soares (Org.); ROBBA, Fabio. Praças brasileiras. São Paulo: Edusp, 2002, p. 311, (Coleção Quapá).

MOTTA, Flávio Lichtenfels. Roberto Burle Marx e a nova visão da paisagem. São Paulo: Nobel, 1983.

MONTERO, Marta Iris. Burle Marx: Paisages líricos. Buenos Aires, 1995. 
PORTER, Tom; GOODMAN, Sue. Manual de técnicas gráficas para arquitectos, diseñadores y artistas. 3. ed. Barcelona: Gustavo Gilli, v. 3, 1985a.

4, 1985b. . Manual de técnicas gráficas para arquitectos, diseñadores y artistas. 4. ed. Barcelona: Gustavo Gilli, v. $2,1989$.

. Manual de técnicas gráficas para arquitectos, diseñadores y artistas. 2. ed. Barcelona: Gustavo Gilli, v.

PORTER, Tom; GREENSTREET, Bob. Manual de técnicas gráficas para arquitectos, diseñadores y artistas. 4. ed. Barcelona: Gustavo Gilli, v. 1, 1987.

Quapá. Projeto de Pesquisa Quapá. Laboratório da Paisagem - Departamento de Projeto fa FAUUSP. Disponível em: <http://www.redealuno.usp.br/quapa. Ascesso em: 9 ago. 2004 e 20 ago. 2005.

RIO DE JANEIRO (Município). Rio Cidade: O urbanismo de volta às ruas. Rio de Janeiro: IPLAN/RIO/MAUAD, 1996.

SANTOS, Nara Rejane Zamberlan; TEIXEIRA, Italo Filippi. Arborização de vias públicas: Ambiente x vegetação. Santa Cruz do Sul: Clube da árvore, 2001.

SEGAWA, Hugo. Ao amor do público: Jardins no Brasil. São Paulo: Studio Nobel/Fapesp, 1996.

QUAPÁ. Paisagismo contemporâneo no Brasil. Projeto Quapá. MACEDO, Sílvio Soares (Coord.). São Paulo: FAUUSP. 2003 (meio digital). 